\title{
Irreducible Water Saturation from Capillary Pressure and Electrical Resistivity Measurements
}

\author{
A.M. Attia ${ }^{1}$, D. Fratta ${ }^{2}$ and Z. Bassiouni ${ }^{3}$ \\ 1 Suez Canal University, Petroleum Engineering, Suez 43721 - Egypt \\ 2 University of Wisconsin-Madison, Geological Engineering Program, Madison, WI 53706 - USA \\ 3 Louisiana State University, Petroleum Engineering, Baton Rouge, LA 70803 - USA \\ e-mail: aattia2@lsu.edu - fratta@wisc.edu - pezab@lsu.edu
}

\begin{abstract}
Résumé - Estimation de la saturation irréductible en eau à partir de la pression capillaire et des mesures de la résistivité électrique - Cet article présente les résultats de mesures de la pression capillaire et de la résistance électrique de trois types de roches : le sable argileux (Berea), le quartz et le calcaire. Nous rapportons également des données expérimentales pour l'indice de résistivité, le facteur de formation, la tortuosité, la pression capillaire et les exposants de saturation en eau de ces roches dans le système air/saumure. Les données de résistivité électrique sont évaluées par la loi d'Archie modifiée. Les résultats des mesures de la pression capillaire et de la résistivité électrique en fonction de la saturation en saumure montrent l'existence de deux saturations irréductibles en eau correspondant à deux phénomènes physiques différents. Les deux valeurs des saturations irréductibles forment des limites hautes et basses qui peuvent être utilisées pour estimer la capacité de la production d'un milieu poreux. L'analyse détaillée des données a aussi montré un changement de valeur de l'exposant de saturation. Ce changement pourrait également être observé à la saturation irréductible en saumure obtenu lors des mesures de pression capillaire.
\end{abstract}

\footnotetext{
Abstract - Irreducible Water Saturation from Capillary Pressure and Electrical Resistivity Measurements - This paper presents the results of capillary pressure and electrical resistivity measurements for three kinds of core specimens: Berea sandstone, Quartz and Limestone. Experimental data of resistivity index, formation resistivity factor, tortuosity, capillary pressure, and water saturation exponent in the air/brine system for these cores are reported. The electrical resistivities data are evaluated using the modified Archie's law. Capillary pressure and electrical resistivity versus brine saturation results show the existence of two irreducible water saturations corresponding to two different physical phenomena. The two values of irreducible brine saturations yield upper and lower limits that can be used to estimate the production capacity of porous media. The detailed analysis of the data has also shown a change in the value of the saturation exponent. This change would be also be observed at the irreducible brine saturation as obtained with capillary pressure data.
} 


\section{INTRODUCTION}

Capillary pressure is an important property used in the evaluation of pore fluid distributions, particularly in the transition zone between wetting and non-wetting phases (water to oil or gas in reservoir formations). This property is important in the evaluation of oil recovery processes. Also it can be used either to calculate oil reserves or to simulate reservoir behavior using computer modeling techniques. The capillary pressure curves also provide data on the irreducible water saturation of a reservoir rock and the entry pressure of the reservoir rock.

Capillary pressure curves are difficult to measure in the field. However, some of the parameters controlling the development of capillary pressure curves may be evaluated from electrical resistivity measurements. Therefore geophysical techniques can be used to estimate the electrical resistivity and the needed petrophysical properties related to wettability, interfacial tension, fluid saturation history, pore size distribution and pore geometry.

This paper presents experimental results obtained from porous plate and two electrode resistivity measurements. The electrical resistivities versus brine saturation data for all cores are evaluated using the modified Archie's law. The results of cementation factor, saturation exponent and tortuosity are related to the capillary pressure and electrical resistivity measurements.

\section{PETROPHYSICAL PARAMETERS}

Petrophysical parameters relate different types of flows: hydraulic, electrical, thermal, chemical, etc. As all types of flows follow similar laws, the parameter that may control one usually controls another (Wang and Anderson, 1992; Mitchell, 1993; Santamarina and Fratta, 2003). For these reasons, geophysical techniques that measure properties related to electrical flow are successfully used to evaluate hydraulic flow parameters. However, the interpretation of the results may be misleading as there are inherent physical differences on the different types of flows and these discrepancies cannot be ignored.

Conduction of electricity through porous media occurs by mainly two mechanisms: movement of ions through the bulk saturating electrolyte and by surface conduction of clay minerals. In the case of porous media with coarse grains, tube-like porous and percolating phases, the electrical resistivity of a formation $\rho_{f}$ can be modeled as:

$$
\frac{1}{\rho_{f}}=\frac{1-\phi}{\rho_{\text {mineral }}}+\frac{\phi S_{r}}{\rho_{\text {pore liquid }}}+\frac{\phi\left(1-S_{r}\right)}{\rho_{\text {pore gas }}}
$$

where $\rho_{\text {mineral }}$ is the resistivity of the rock mineral, $\rho_{\text {pore liquid }}$ is the electrical resistivity of the pore fluid, $\rho_{\text {pore gas }}$ is the resistivity of the pore gas, $\phi$ is the porosity. $S_{r}$ is the degree of pore liquid saturation. In most oil-bearing formation rocks, the rock mineral and pore gas are insulators.
One of the drawbacks of this formulation is that Equation 1 fails to model the surface conduction in a formation. The effect of surface conductance in a formation can be estimated by adding a surface conduction term to Equation 1 (Klein and Santamarina, 2003; Santamarina et al., 2001). Then, the resistivity of the formation becomes:

$$
\rho_{f}=\frac{\rho_{\text {pore liquid }}}{\phi S_{r}+(1-\phi) \Theta \frac{\gamma_{\min }}{g} S_{s} \rho_{\text {pore gas }}}
$$

where $\Theta$ is the surface conduction, $\gamma_{\min }$ is the mineral unit weight, $g$ is the acceleration of gravity, and $S_{S}$ is the specific surface of the formation mineral.

Figure 1 shows the effect of porosity and surface conduction on different saturated rock formations. This figure is based in Equation 2, which in spite of its limitations yields boundaries to the evaluation of the different parameters. The proper interpretation of this figure provides a solid base for the analysis of geophysical studies. Furthermore, the electrical resistivity of a porous medium is also related to the micro-structural properties, including porosity, pore geometry and surface morphology of the mineral grains lining the pores. Archie (1942) proposes the following semi-empirical relationship:

$$
\rho=a \phi^{-m} S_{r}^{-n} \rho_{f}
$$

where $a, m$, and $n$ are experimental determined factors.

The factor $a$ varies between 0.5 and 2.5. The factor $m$ is also known as the cementation factor and it varies between 1.3 and 2.5 for most rocks. The cementation factor is 1.3 for unconsolidated, clean glass beads, 2 for sandstone formation, and around 5 for carbonates (Telford et al., 1990; Mavko et al., 1998).

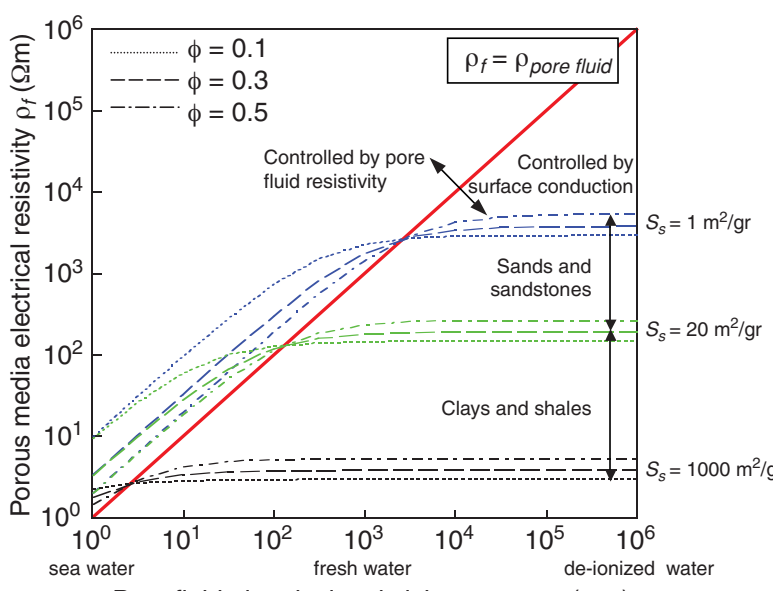

Pore fluid electrical resistivity $\rho_{\text {pore liquid }}(\Omega \mathrm{m})$

Figure 1

Typical electrical resistivity trends for non-conductive and saturated mineral rocks as modeled with Equation 2 (surface conduction $\Theta=1.4 \cdot 10^{-9} \mathrm{~S}$ ). 
The factor $n$ is known as the water saturation exponent and it has been related to several petrophysical parameters. Typically, its value is around 2 in water-wet formations and it is assumed constant for clean, sandy like formations (Archie, 1942; Mavko et al., 1998). Lewis et al. (1988), Longeron et al. (1989a, b), Donaldson and Siddiqui (1989), and Moss et al. (2000) found that the saturation exponent $n$ increases to values as high as ten in oil wet formations. Furthermore, Diederix (1982), Anderson (1986), Longeron et al. (1989a, b), and Worthington and Pallat (1992) found that the saturation exponent is not always constant over the whole saturation range in disagreement with the early work by Archie (1942).

The formation resistivity factor $F_{R}$, is the ratio between the resistivity, $\rho_{o}$, of the rock at $100 \%$ saturated with conducting brine to the resistivity $\rho_{\text {pore liquid }}$ of this brine. This ratio depends on the lithological characteristics of the rock formation and the effective porosity. The formation resistivity factor is sometimes expressed as function of the percolation porosity $\phi_{o}$ that is the minimum porosity that connects the pores in a rock formation:

$$
F_{R}=\left(\phi-\phi_{o}\right)^{-m}
$$

The resistivity index $I_{R}$ is expressed by Archie (1942) as:

$$
\frac{\rho_{f}}{\rho_{0}}=I_{R}=S_{r}^{-n}
$$

Swanson (1985) found that the resistivity-saturation plot shows a change in the slope at a saturation point where the corresponding capillary pressure curve indicate a transition from macroporosity to microporosity.

Finally, tortuosity is defined as the ratio of the ionic path $L_{i}$ over the distance between the electrodes $L_{R}$. alternatively, according to Tiab and Donaldson (1996), tortuosity is defined as:

$$
\tau=1+\frac{\phi_{\text {trapped }}}{\phi_{\text {channel }}}=1+\frac{\phi-\phi^{m}}{\phi^{m}}
$$

where $\phi_{\text {trapped }}$ and $\phi_{\text {channel }}$ are porosities that correspond to the porosity of the trapped fluid that does not contribute to electrical conduction and to the porosity of the fluid that contributes to the conduction. In addition, Attia (2005) found that the tortuosity factor is affected by porosity, cementation factor and degree of brine saturation.

\section{EXPERIMENTAL TESTS}

This paper presents petrophysical properties of eight Berea sandstone, twelve Quartz and ten Limestone rock specimens. The experimental results were obtained using $5 \% \mathrm{NaCl}$ brine solutions. The petrophysical properties of the specimens are tabulated in Tables 1 through 4. During the experimental testing program the following petrophysical parameters were determined for each specimen: pore size distribution, saturation versus capillary pressure curves, and electrical resistivity versus saturation curves. These data are obtained using two measurement techniques:

- porous plate

- impedance measurement methods

These two methodologies permit the evaluation of process of de-saturation of rock cores and the behavior of the water saturation exponent $n$. The description of testing procedure is as follows.

\subsection{Porous Plate Method}

The porous plate method was used to measure the capillary pressure-saturation curves for different types of core specimens (Berea sandstone, Quartz and Limestone) with $5 \% \mathrm{NaCl}$ brine solution. The procedure has several steps, including:

- Porous plate saturation: the procedure indicated in the manual "Soil Moisture Capillary Pressure Cell" manual (Core Lab Instruments, 2000) is used to fully saturate the porous stone saturation.

- Core specimen preparation: the core specimens are measured, cleaned, dried, weighed, and saturated with the $\mathrm{NaCl}$ brine solution. After the saturation process is

\begin{tabular}{|c|c|c|c|c|c|}
\hline $\begin{array}{l}\text { Specimen } \\
\text { Number }\end{array}$ & Description & $\begin{array}{c}\text { Diameter } \\
D_{R}(\mathrm{~m})\end{array}$ & $\begin{array}{l}\text { Length } \\
L_{R}(\mathrm{~m})\end{array}$ & $\begin{array}{c}\text { Total Volume } \\
\qquad V_{R}\left(\mathrm{~m}^{3}\right)\end{array}$ & $\begin{array}{c}\text { Dry mass } \\
M_{d}(\mathrm{~g})\end{array}$ \\
\hline 21 & Homogeneous & 0.0380 & 0.0471 & $5.34 \cdot 10^{-5}$ & 104.28 \\
\hline 23 & Vertical layering & 0.0373 & 0.0508 & $5.55 \cdot 10^{-5}$ & 116.60 \\
\hline 24 & Horizontal layering & 0.0374 & 0.0502 & $5.51 \cdot 10^{-5}$ & 115.53 \\
\hline 30 & Vertical layering & 0.0377 & 0.0384 & $4.29 \cdot 10^{-5}$ & 88.49 \\
\hline 31 & Vertical layering & 0.0377 & 0.0323 & $3.61 \cdot 10^{-5}$ & 74.57 \\
\hline 32 & Vertical layering & 0.0381 & 0.0368 & $4.20 \cdot 10^{-5}$ & 83.69 \\
\hline 33 & Vertical layering & 0.0381 & 0.0359 & $4.09 \cdot 10^{-5}$ & 82.55 \\
\hline 34 & Vertical layering & 0.0373 & 0.0377 & $4.12 \cdot 10^{-5}$ & 86.79 \\
\hline
\end{tabular}

TABLE 1

Geometric properties of tested Berea sandstone specimens 
completed the core specimens are re-weighed to determine the porosity $\phi$ (Table 1).

- Testing procedure: with the core specimen placed on top of the porous plate, the air-brine capillary pressure procedure is ready to begin (Fig. 2). A certain air pressure $p_{a}$ is applied to the top of the core specimen and the water within the core specimen is allowed to drain through the porous stone. The capillary pressure $p_{c}$ is equal to the difference between the air pressure and the water pressure. When equilibrium is achieved, the air pressure and the top of the cell are removed. Then the core specimen is weighed and the degree saturation is calculated at the applied capillary pressure $p_{c}$. The specimen is returned to the cell and the procedure is repeated for higher values of the capillary pressure $p_{c}$.

The capillary pressure versus saturation curve is obtained and then used to estimate the pore size distribution.

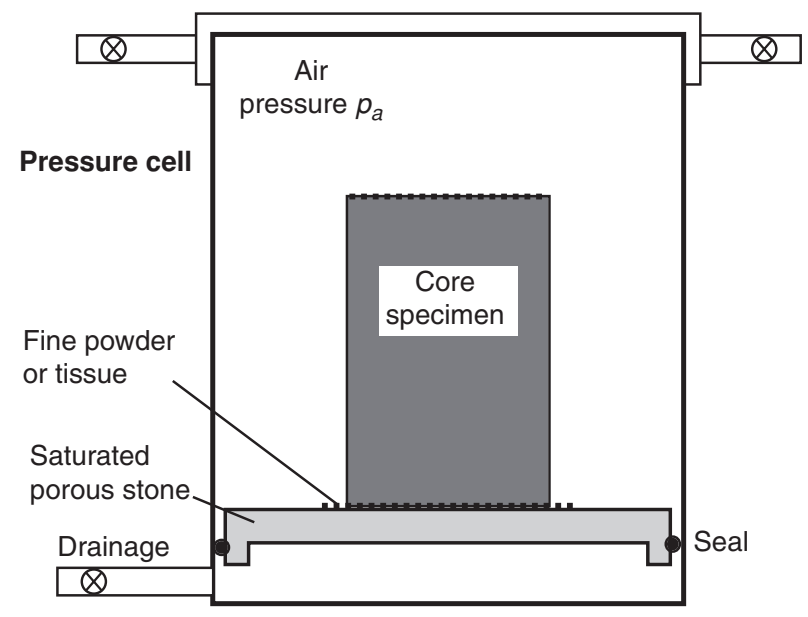

Figure 2

Schematic of the capillary versus saturation cell (after Core Lab Instruments, 2000).

\subsection{Impedance Measurements Method}

An impedance analyzer Hewlett Packard 4279A LCZ meter is used to measure the electrical resistivity of the Berea sandstone (Berea as example) core specimens under varying degrees of brine saturation. The LCZ meter is capable of measuring inductance, capacitance, dissipation, quality factor, impedance magnitude, and phase angle in equivalent parallel and series circuits (Hewlett Packard, 1984). These measurements cover a frequency range from $100 \mathrm{~Hz}$ to $20 \mathrm{kHz}$. The HP 4297A model is controlled by a personal computer via an HP-IB card and the Agilent VEE Pro software. The card and the software allow the digitalization of the data for the analysis and interpretation of the measurement results.

Figure 3 presents a sketch of the testing setup, measurement system, and data collection system. The measurements include impedance magnitude and phase angle from $100 \mathrm{~Hz}$ to $20 \mathrm{kHz}$ in steps of $100 \mathrm{~Hz}$. The impedance analyzer is equipped with four coaxial BNC connectors and with an HP 16047A Test Feature. This feature combines the high and low voltage and current terminals and permits two terminal measurements of the electrical properties of the specimens. The two-terminal measurement method is a simple procedure to implement, however it has some drawbacks over competitive methods (i.e., four-electrode method - see for example Santamarina et al., 2001). One of the biggest drawbacks is the problem of electrode polarization. This phenomenon is explained next.

The measurement of the electrical resistivity of rock specimens involves the analysis of an equivalent electrical circuit where the rock core specimen is in series with the electrodes and the required peripheral electronics. The rock electrode interface feels the movement of ions on the rock specimen, and the movement of electrons on the electronic circuit. At the interface, where the use blocking electrodes is common (i.e., electrodes that do not experience oxidationreduction), ions accumulate at the interface causing electrode polarization.

The phenomenon of electrode polarization may be modeled by adding a thin air-gap $L_{g a p}$ at the interface between the electrode and the rock (Klein and Santamarina, 1997). Consider a parallel plate capacitor with a specimen of thickness $L_{R}$ and cross sectional area A (Fig. 4). The rock can be represented as a resistor and a capacitor in parallel, with effective electric resistivity $\rho_{R}(\Omega \mathrm{m})$ and dielectric permittivity $\varepsilon_{R}(\mathrm{~F} / \mathrm{m})$. Then, the electrical impedance for the equivalent circuit $Z_{e q}$ is:

$$
\begin{aligned}
Z_{e q} & =\frac{1}{j 2 \pi f C_{g a p}}+\frac{1}{\frac{1}{R_{R}}+j 2 \pi f C_{R}} \\
& =\frac{1}{A}\left[\frac{L_{g a p}}{j 2 \pi f \varepsilon_{o}}+\frac{L_{R}}{\frac{1}{\rho_{R}}+j 2 \pi f \varepsilon_{R}}\right]
\end{aligned}
$$

where $C_{\text {gap }}=\varepsilon_{\mathrm{o}} A / L_{\text {gap }}$ is the capacitance at the blocking electrodes, $R_{R}=\rho_{R} L_{R} / A$ and $C_{R}=\varepsilon_{\mathrm{R}} A / L_{R}$ are the resistance and capacitance of the core specimen, and $A$ is the cross sectional area of the capacitor.

The results presented in Figure 5 show that the effects of electrode polarization become negligible with smaller separation gap $L_{\text {gap }}$ (Fig. 5a) and that the transition frequency is smaller with the greater rock resistivity $\rho_{R}$ (Fig. $5 a-$ Santamarina et al., 2001). Therefore, electrode polarization effects are not expected in high-frequency laboratory 


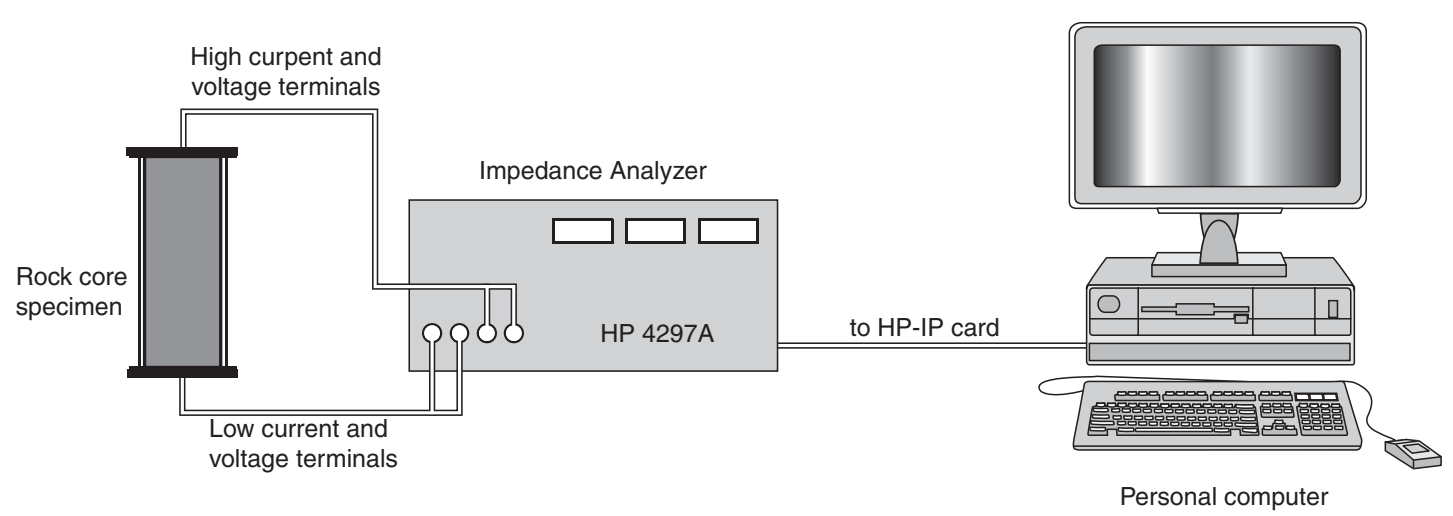

Figure 3

Sketch of the electrical resistivity measurement setup.

Test Setup

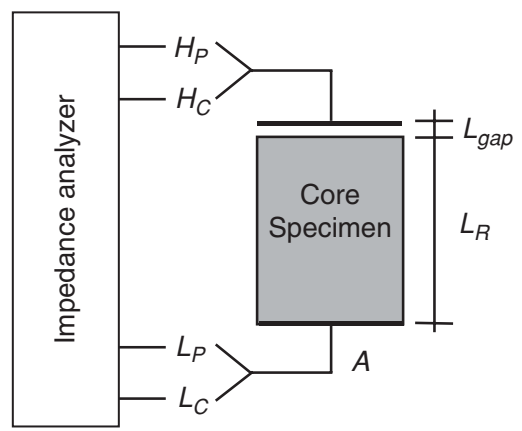

Equivalent Circuit

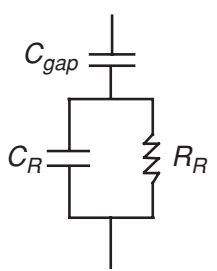

Figure 4

Equivalent two-electrode circuit and the effect of blocking electrodes.

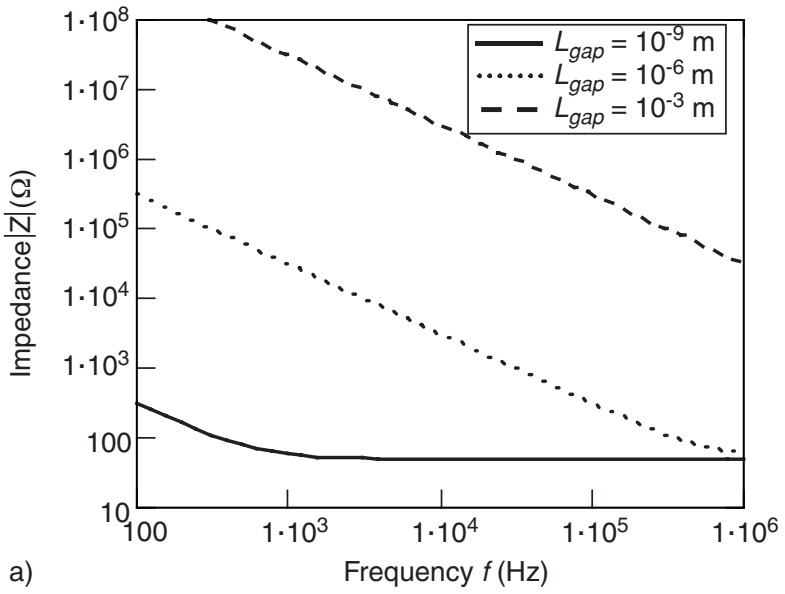

Figure 5

Effect of electrode polarization on impedance measurement. a) Varying electrode $L_{g a p}$ for constant rock resistivity $\rho_{R}=1 \Omega$ m;

b) Varying rock resistivity for constant electrode gap $L_{\text {gap }}=10^{-6} \mathrm{~m}\left(L_{R}=0.0285 \mathrm{~m}, A=6.4 \cdot 10^{-4} \mathrm{~m}, \varepsilon_{\mathrm{o}}=8.85 \cdot 10^{-12} \mathrm{~F} / \mathrm{m}\right.$ and $\left.\varepsilon_{\mathrm{R}}=20 \varepsilon_{\mathrm{o}}\right)$.

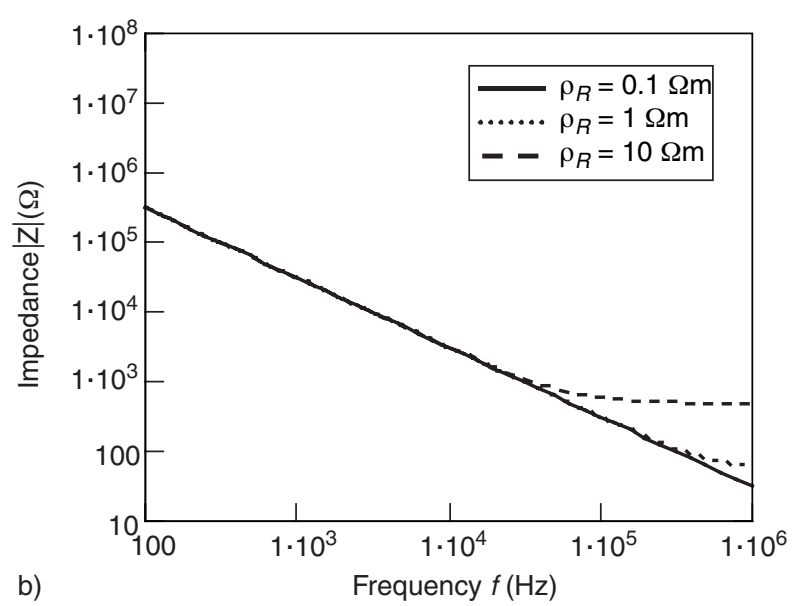

b) 
measurements. However, due to specifications of the HP Impedance Analyzer, the range of measurement extend the low frequency range, where electrode polarization dominates the impedance measurement unless the deportation gap $L_{g a p}$ is very small or the resistivity of the measured material is high.

Two different types of electrodes are used in these measurements: Al foil and silver-based paint. The $\mathrm{Al}$ foil may act as a blocking electrode if low rate of chemical reaction occurs. However the problem with the $\mathrm{Al}$ foil electrodes is that separation gap $L_{g a p}$ is about the same order of magnitude as the sandstone grain size $\left(D_{50} \approx 0.1 \mathrm{~mm}\right)$ and this separation gap may change for different specimen and the applied normal pressure. The silver paint electrodes have been used in the past (see for example Longeron et al., 1989a). The advantage of this type of electrodes is that they reduce the separation gap. Furthermore, the gap remains constant throughout the testing series and it does not depend on the normal pressure.

Figure 6 shows the measured impedance on Berea sandstone core specimen 22 using the $\mathrm{Al}$ foil electrodes and silver-based paint for different saturation $S_{r}$. It is clear that the $\mathrm{Al}$ foil electrode measurements are controlled by the effect of electrode polarization (Fig. 6a) while the silver-based paint electrode measurement removes most of the effect of electrode polarization in the impedance response (Fig. $6 b$ ). Furthermore, the transition frequency is smaller when the resistivity of the specimen is greater, as observed by comparing side-by-side the two set of results. In light of these observations the silver-based paint electrodes are selected for the electrical resistivity measurements.

\subsection{Description of Electrical Resistivity Measurement Methodology}

The core specimens are cleaned, dried in the oven, painted on each side, evacuated, and then saturated with $5 \% \mathrm{NaCl}$ brine solution $\left(\rho_{\text {pore liquid }}=0.161 \Omega \mathrm{m}\right)$ by applying vacuum for 12 hours to the submerged specimens. The specimens are then removed and their surfaces are dried with tissue paper. This action renders the specimen saturated-surface dry. Then the specimens are weighed to determine the degree of saturation and placed in the cell to measure the impedance. After each measurement, the specimen is placed in a covered container to stabilize its moisture content till the next set of measurement. This technique reduces the instability of the capillary pressure when the measurements are taken.

\section{TESTS RESULTS}

A set of different petrophysical properties are collected including capillary pressure curves (Fig. 7), pore size distribution (Fig. 8), and electrical resistivity versus degree of saturation (Fig. 9) for eight Berea sandstone core specimens. Figure 7 shows that all specimens have similar capillary pressure saturation curves except for the Berea sandstone core specimen 21. All the other core specimens show that the irreducible water saturation is nearly 0.33 , while specimen 21 shows it to be 0.23 . This specimen is also the only one that shows no layering (Table 1). Furthermore, the pore size distribution also shows a marked difference in the characteristics of specimen 21 (Fig. 8). The average parameters for the Berea sandstone, Quartz (very fine grained) and Limestone specimens are summarized in Tables 2, 3 and 4 respectively.
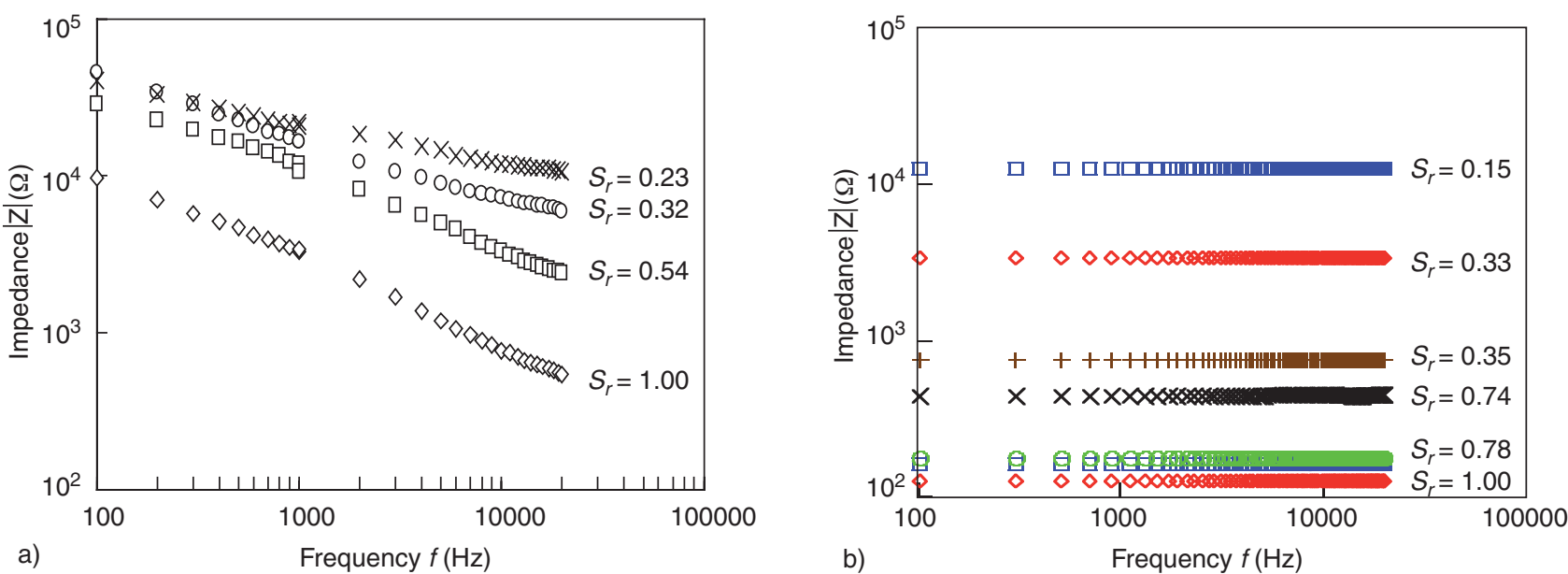

Figure 6

Effect of type of electrode on the measurement of the impedance on Berea sandstone core specimen 22.

a) Al foil electrodes; b) Silver-based paint electrodes. Electrode polarization controls the impedance measurement with the Al foil electrodes 
TABLE 2

Summary of porosity, tortuosity, ionic length, formation resistivity factor, cementation factor, and water saturation exponent for all tested Berea sandstone core specimens (Attia, 2005)

\begin{tabular}{|c|c|c|c|c|c|c|}
\hline $\begin{array}{l}\text { Specimen } \\
\text { Number }\end{array}$ & $\begin{array}{c}\text { Porosity } \\
\phi\end{array}$ & $\begin{array}{c}\text { Tortuosity } \\
\tau\end{array}$ & $\begin{array}{c}\text { Ionic length } \\
L_{i}=L_{R} \sqrt{\tau}(\mathrm{m})\end{array}$ & $\begin{array}{c}\text { Formation } \\
\text { resistivity factor } F_{R}\end{array}$ & $\begin{array}{c}\text { Cementation } \\
\text { factor }\end{array}$ & $\begin{array}{c}\text { Water saturation } \\
\text { exponent } n\end{array}$ \\
\hline 21 & 0.207 & 3.84 & 0.092 & 18.6 & 1.85 & 2.12 \\
\hline 23 & 0.191 & 4.35 & 0.106 & 22.8 & 1.89 & 1.80 \\
\hline 24 & 0.192 & 4.26 & 0.104 & 22.2 & 1.88 & 2.42 \\
\hline 30 & 0.186 & 3.78 & 0.075 & 20.3 & 1.79 & 1.93 \\
\hline 31 & 0.187 & 4.71 & 0.070 & 25.2 & 1.92 & 1.98 \\
\hline 32 & 0.181 & 4.04 & 0.074 & 22.3 & 1.82 & 1.62 \\
\hline 33 & 0.182 & 3.82 & 0.070 & 21.0 & 1.79 & 2.02 \\
\hline 34 & 0.192 & 4.48 & 0.080 & 23.3 & 1.91 & 1.96 \\
\hline
\end{tabular}

TABLE 3

Summary of porosity, quartz flour content, formation resistivity factor, and water saturation exponents for all tested Quartz sandstone core specimens (after Attia, 2005)

\begin{tabular}{|c|c|c|c|c|c|}
\hline $\begin{array}{l}\text { Specimen } \\
\text { Number }\end{array}$ & $\begin{array}{c}\text { Porosity } \\
\phi\end{array}$ & $\begin{array}{c}\text { Quartz } \\
\text { Flour (\%) }\end{array}$ & $\begin{array}{c}\text { Formation } \\
\text { resistivity factor } \\
F_{R}\end{array}$ & $\begin{array}{c}\text { Water saturation } \\
\text { exponent } n \\
\text { (for } S_{r}<0.32 \text { ) }\end{array}$ & $\begin{array}{c}\text { Water saturation } \\
\text { exponent } n \\
\text { (for } S_{r}>0.32 \text { ) }\end{array}$ \\
\hline 2 & 0.258 & 100 & 1.31 & 1.95 & 1.67 \\
\hline 6 & 0.293 & 100 & 1.44 & 2.48 & 1.76 \\
\hline 14 & 0.292 & 100 & 1.48 & 3.08 & 1.86 \\
\hline 18 & 0.224 & 80 & 1.38 & 2.56 & 1.73 \\
\hline 22 & 0.265 & 80 & 1.61 & 2.62 & 1.86 \\
\hline 28 & 0.253 & 80 & 1.61 & 3.18 & 1.93 \\
\hline 32 & 0.194 & 60 & 1.64 & 3.60 & 1.94 \\
\hline 38 & 0.239 & 60 & 1.81 & 2.94 & 1.79 \\
\hline 42 & 0.222 & 60 & 1.83 & 2.65 & 1.75 \\
\hline 48 & 0.201 & 40 & 1.71 & N/A & 1.98 \\
\hline 54 & 0.201 & 40 & 2.06 & 3.60 & 1.61 \\
\hline 58 & 0.187 & 40 & 1.86 & 3.73 & 1.77 \\
\hline
\end{tabular}

TABLE 4

Summary of porosity, tortuosity factor, formation resistivity factor, and water saturation exponents for all tested Limestone core specimens

\begin{tabular}{|c|c|c|c|c|c|}
\hline $\begin{array}{l}\text { Specimen } \\
\text { Number }\end{array}$ & $\begin{array}{c}\text { Porosity } \\
\phi\end{array}$ & $\begin{array}{c}\text { Tortuosity } \\
\tau\end{array}$ & $\begin{array}{c}\text { Formation } \\
\text { resistivity factor } F_{R}\end{array}$ & $\begin{array}{c}\text { Water saturation } \\
\text { exponent } n \\
\text { (for } S_{r}<0.68 \text { ) }\end{array}$ & $\begin{array}{c}\text { Water saturation } \\
\text { exponent } n \\
\text { (for } S_{r}>0.68 \text { ) }\end{array}$ \\
\hline $1 \mathrm{~L}$ & 0.14 & 1.44 & 30.3 & N/A & N/A \\
\hline $2 \mathrm{~L}$ & 0.145 & 1.44 & 29.7 & N/A & N/A \\
\hline $3 \mathrm{~L}$ & 0.142 & 1.43 & 29.6 & 3.67 & 2.20 \\
\hline $4 \mathrm{~L}$ & 0.143 & 1.44 & 30.1 & 3.36 & 1.97 \\
\hline $5 \mathrm{~L}$ & 0.087 & 1.27 & 29.7 & 3.67 & 1.86 \\
\hline $6 \mathrm{~L}$ & 0.143 & 1.43 & 29.4 & 3.70 & 2.14 \\
\hline $18 \mathrm{~L}$ & 0.142 & 1.43 & 29.2 & 4.36 & 2.23 \\
\hline $19 \mathrm{~L}$ & 0.143 & 1.45 & 31.2 & 4.55 & 2.29 \\
\hline $20 \mathrm{~L}$ & 0.142 & 1.46 & 32.0 & 3.88 & 2.16 \\
\hline $21 \mathrm{~L}$ & 0.158 & 1.49 & 31.2 & 1.41 & 3.01 \\
\hline
\end{tabular}



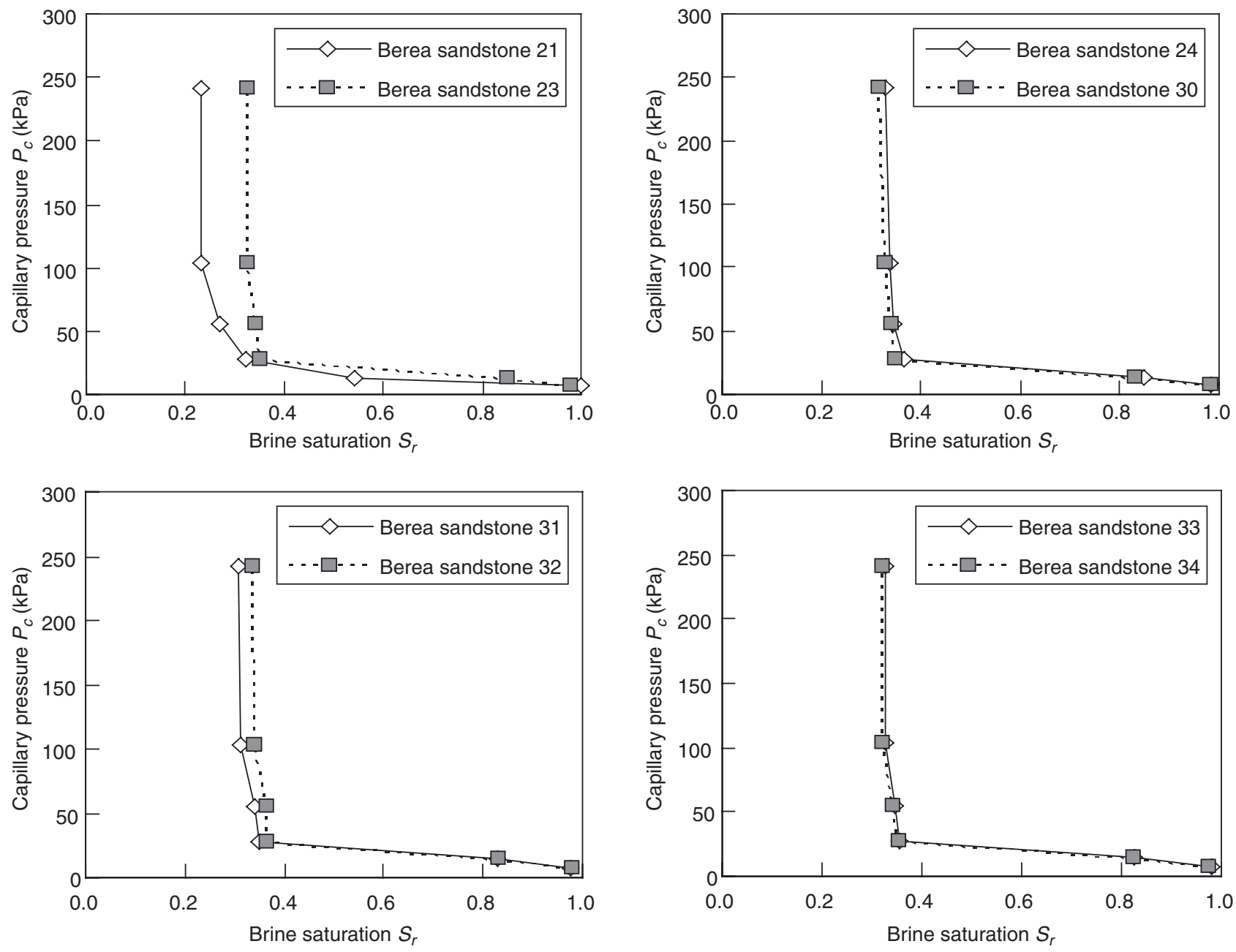

Figure 7

Capillary pressure-brine saturation curves for all eight Berea sandstone core specimens.

\section{DISCUSSION}

The electrical resistivity and capillary pressure curves for the Berea sandstone, Quartz, and Limestone cores show similar behavior: as the brine saturation decreases, the values of the petrophysical parameters increase.

However, the point of irreducible brine saturation in the capillary pressure curve differs from the point where there is a break in the electrical conductivity path (see Figs. 10-12). This difference is due to the different nature of the two processes. The capillary pressure versus saturation curve is obtained by applying gas pressure to the brine phase until the air percolates through the porous matrix. This percolation point is the irreducible brine saturation. It is "irreducible" only in the sense that the air pressure cannot "push" the brine out beyond this point. Nevertheless, at the irreducible brine saturation point, the electrolyte paths are still active and there are no sudden changes in the electrical conduction behavior. The change in the electrical conduction only occurs at a lower degree of saturation, when the conduction paths are broken and the resistivity rapidly increases.

The observations presented in Figures 10 through 12 can be clearly explained with the help of Figure 13. This figure shows the process of evacuation (drying) using the porous stone method. As the capillary pressure (air pressure) increases, it pushes the brine out of the porous medium decreasing the saturation and increasing the electrical resistivity of the medium (Figs. 13a-c). This process continues until the air paths between the top and bottom of the specimen are continuous (Fig. 13d). At this point, the irreducible water saturation in the "capillary pressure sense" is reached. A further increase in the capillary pressure cannot remove anymore brine and the electrical resistivity should remain constant (Fig. 13e). However, if the medium is 
allowed to dry due to evaporation the electrical resistivity would still slowly increase because the ionic paths will be strangled as the brine saturation decreases. This process continues until all the ionic paths are broken and electrical resistivity reaches its final plateau (Fig. 13f). From Equation 1, the theoretical electrical resistivity of the plateau is approximately equal to:

$$
\rho_{f}=\left(\frac{1-\phi}{\rho_{\text {mineral }}}+\frac{\phi\left(1-S_{r}\right)}{\rho_{\text {pore gas }}}\right)^{-1}
$$

The irreducible brine saturation obtained with either method can not be directly used to evaluate the production potential of a reservoir. They can only be considered as upper and lower limits of the irreducible brine saturation. These two measured levels of brine saturation yield an indication of the percolation phenomena. The true value of the irreducible water saturation will depend on the production method and the affinity of the mineral to the fluid.

One common parameter used in the evaluation of the production potential of a formation is the saturation exponent. The saturation exponent in the measured core specimens is not constant for different degree of saturations as indicated by Archie (1942) even for clean Berea sandstone (Anderson, 1986). Figures 14a, 15a and 16a show that average saturation coefficient changes from 1.60 to $2.70,2.00$ to 3.50 and 2.09 to 3.84 for Berea sandstone, Quartz, and Limestone core specimens respectively, when the degree of saturation drops below a certain value. The break in the slope of $\log \left(I_{R}\right)$ versus $\log \left(S_{r}\right)$ occurs at the point that coincides with the capillary pressure-based irreducible brine saturation (see Figs. 14b, 15b and 16b) and it does help in the evaluation of the electrical resistivity-based irreducible saturation that provides the higher bound in the production potential of the formation.
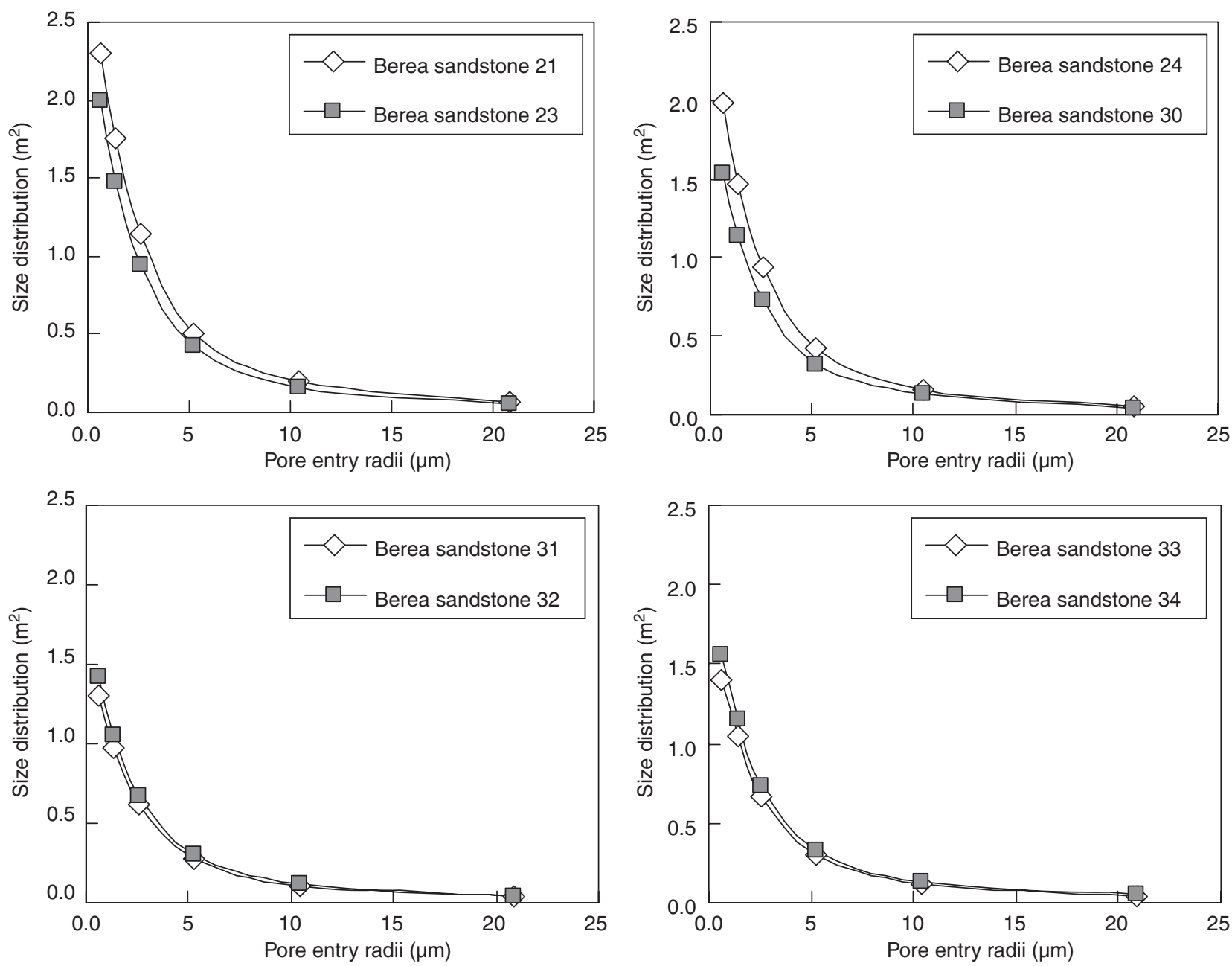

Figure 8

Pore size distribution for all eight Berea sandstone core specimens. 

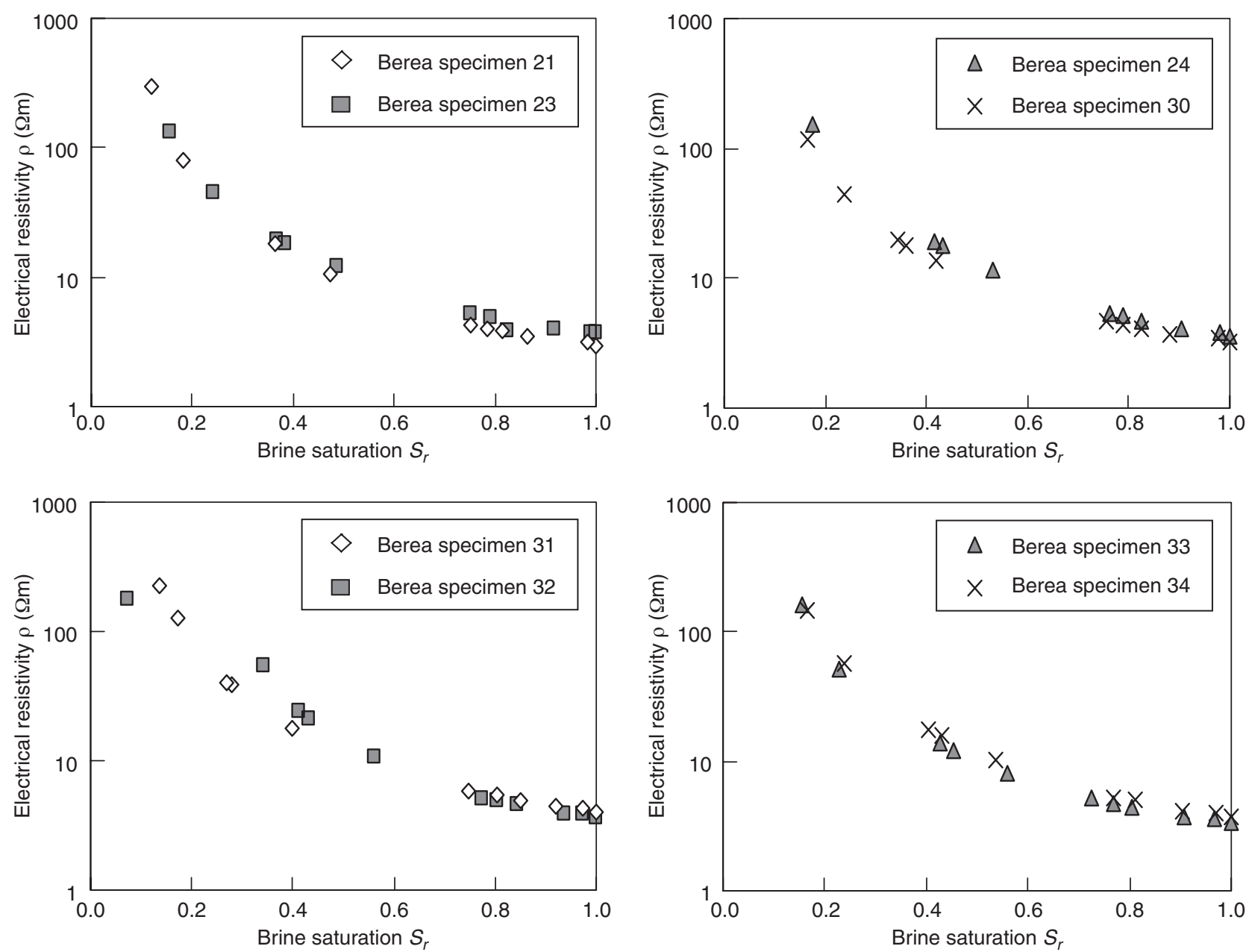

Figure 9

Electrical resistivity versus brine saturation for all eight Berea sandstone core specimens.

The change in slope seems to indicate the beginning of the process that produces the rupture of electrolyte paths in the porous media. At degrees of saturation higher than the point of sudden change in the saturation exponent, the increase of electrical resistivity seems to occurs only due to the decrease in the cross sectional area of continuous electrolyte paths. Then a change in the behavior seems to occur at the point of capillary pressure-based irreducible brine saturation where the brine phase still percolates at a minimum through the surface of the porous. At this point the isolating non-wetting phase zone starts to become dominant over the conductive wetting phase.

Finally, the evaluation of tortuosity versus brine saturation is presented in Figure 17. The tortuosity is here calculated by modifying Equation 6 to include the effect of saturation:

$$
\begin{array}{r}
\tau=1+\frac{\phi_{\text {trapped }}}{\phi_{\text {channel }}\left(S_{r}-S_{r i E}\right)}=1+\frac{\phi-\phi^{m}}{\phi^{m}\left(S_{r}-S_{r i E}\right)} \\
\text { for } S_{r}>S_{r i E}
\end{array}
$$

where $S_{r i E}$ is the irreducible water in the electrical resistivity sense. This new equation assumes that the trapped porosity does not contribute to the electrical conductivity and the tortuosity reaches infinite value when all the brine in the channel is removed (Fig. 17a). The normal-normal plot (Fig. 17a) clearly shows the value of lower value of the irreducible water saturation, while it does not present a clear break in the log-log plot (Fig. 17b). The tortuosity provides an indication of the twisting of ionic path and it appears as it only changes at a slowly rate and it does not suddenly alter the conduction paths until the last brine percolation path is broken.

\section{CONCLUSIONS}

This paper presents the results of capillary pressure and electrical resistivity versus degree of saturation for three types of rocks. Berea sandstone, Quartz and Limestone core specimens were measured with the porous stone method and with the two-electrode method to evaluate the capillary 

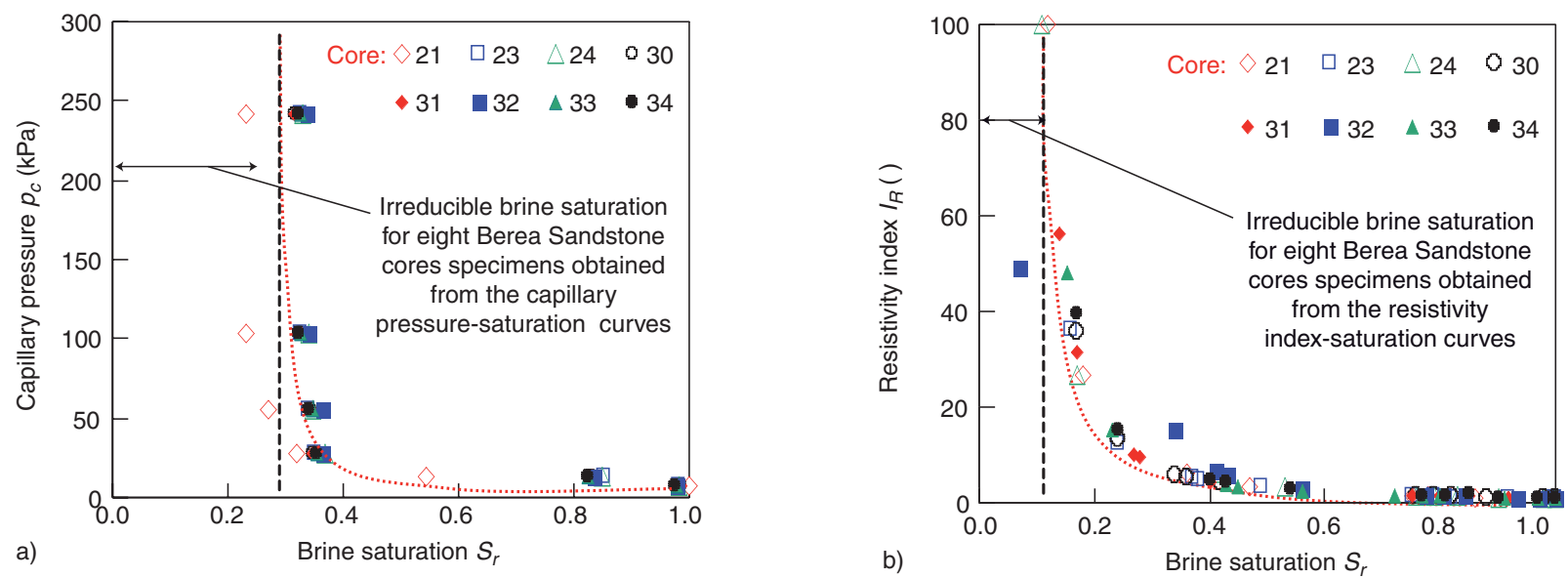

Figure 10

Capillary pressure and resistivity index versus brine saturation in Berea sandstone core specimens. Two irreducible water saturations are identified: one for capillary pressure and another one for the electrical properties.
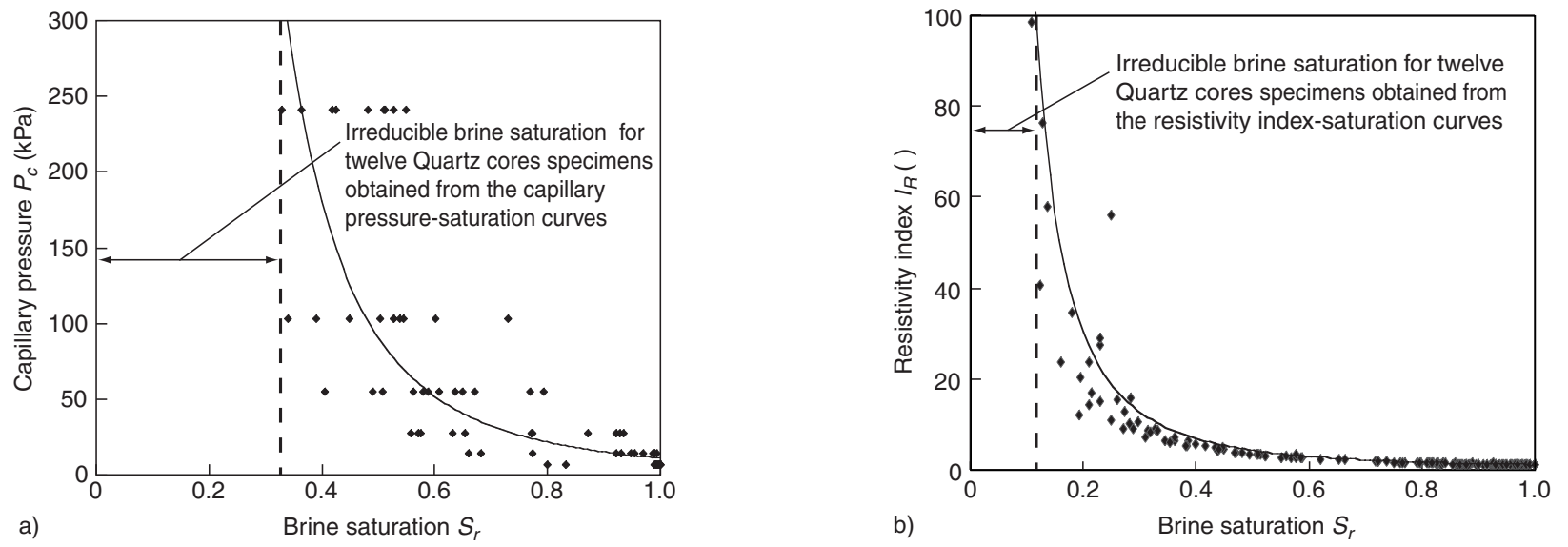

Figure 11

Capillary pressure and resistivity index versus brine saturation in twelve Quartz (very fine-grained) sandstone core specimens. Two irreducible water saturations are identified: one for capillary pressure and another one for the electrical properties.

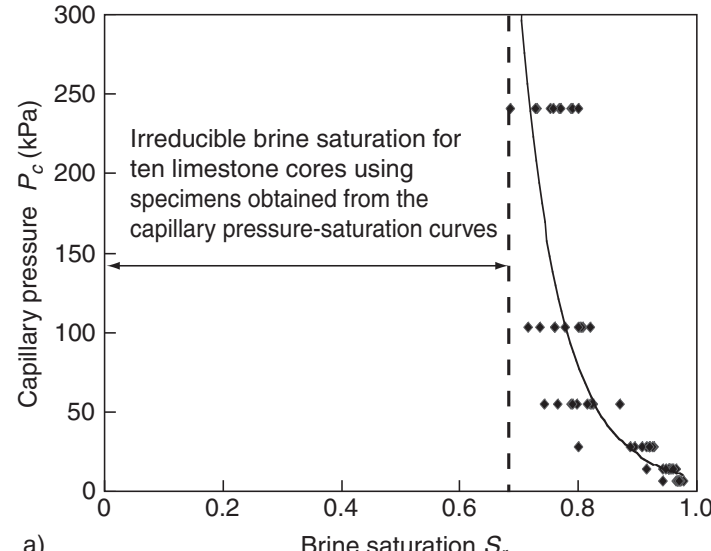

Figure 12

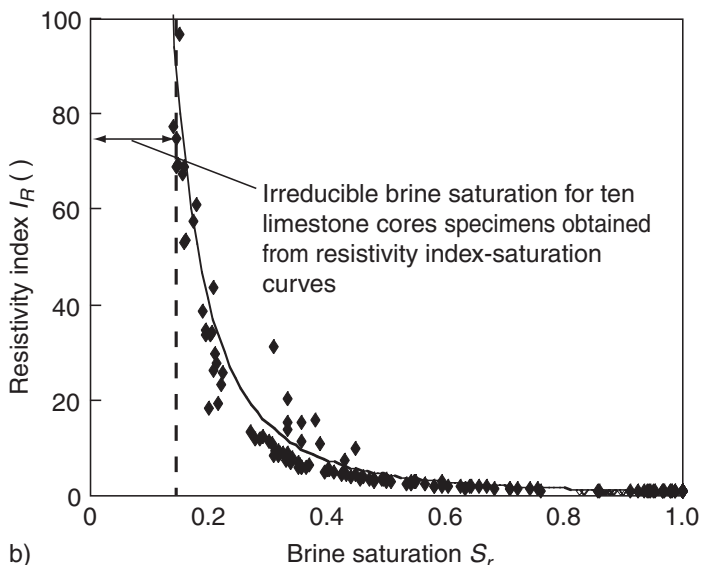

b)

Capillary pressure and resistivity index versus brine saturation in ten Limestone core specimens. Two irreducible water saturations are identified: one for capillary pressure and another one for the electrical properties. 
$p_{c}$ (air pressure)

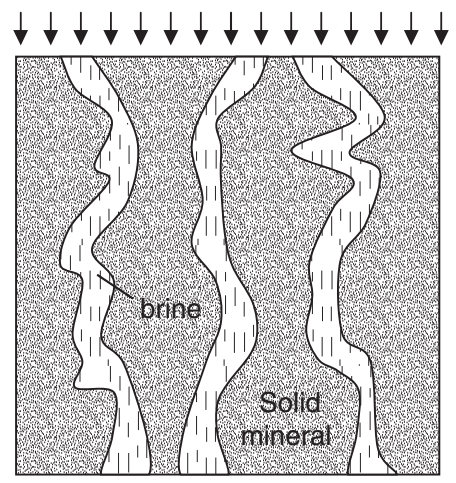

a)

Increasing $p_{c}$

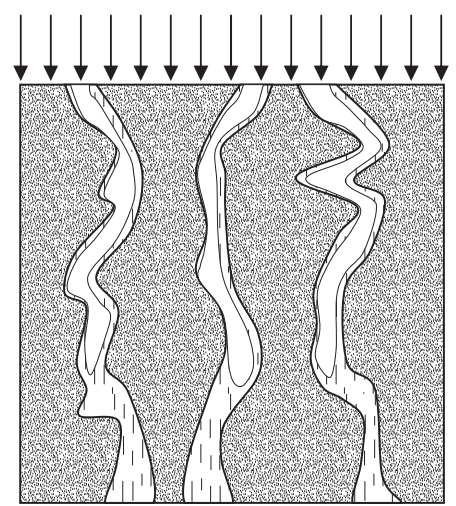

c)

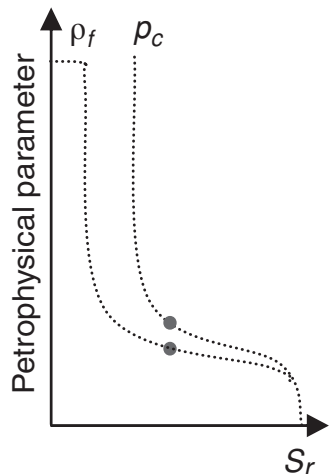

Increasing $p_{c}$

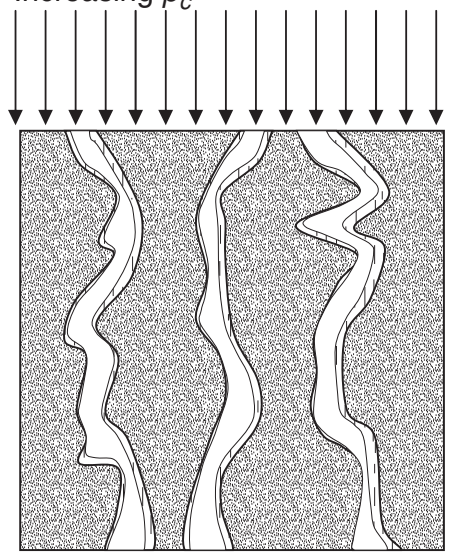

Evaporation and reduction of brine saturation

e)

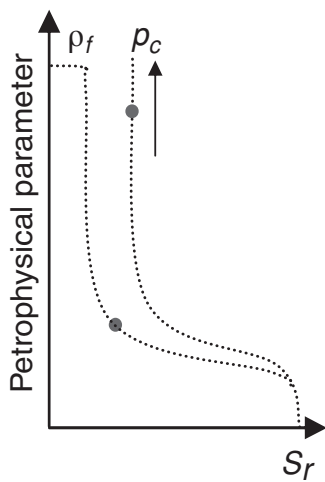

Figure 13

Effect of percolation on the capillary pressure and electrical resistivity measurements.

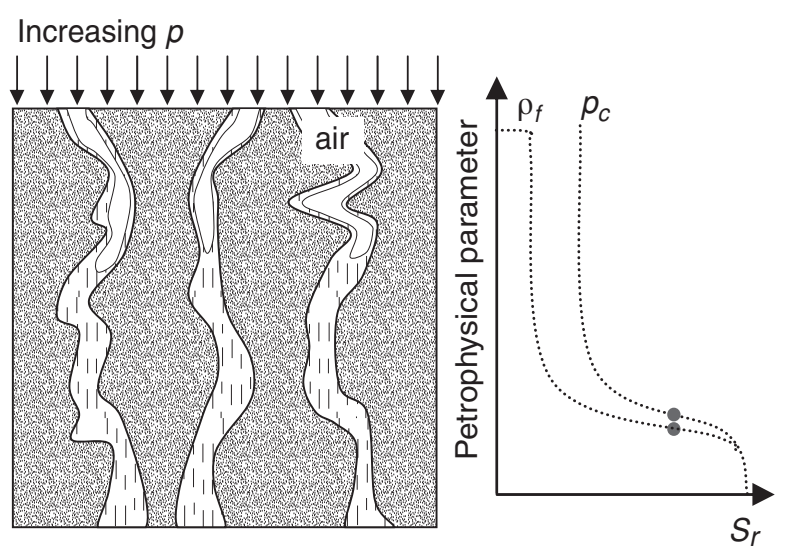

b)

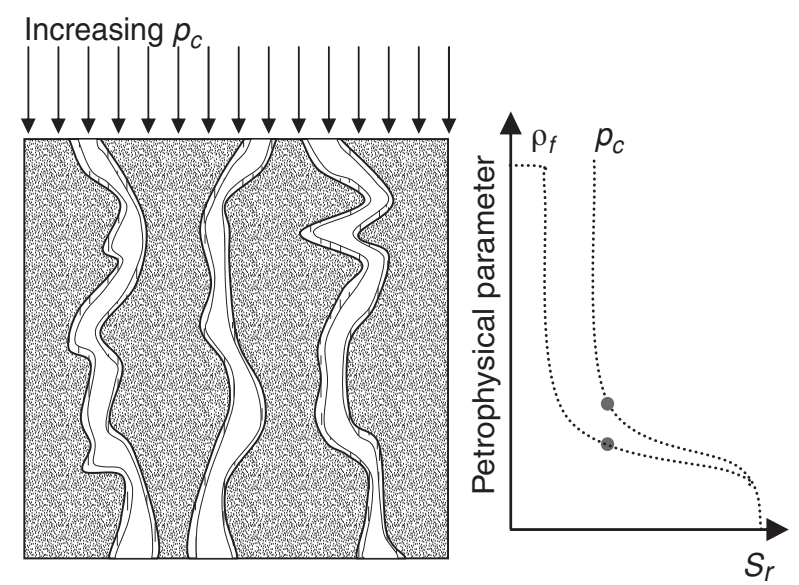

d)

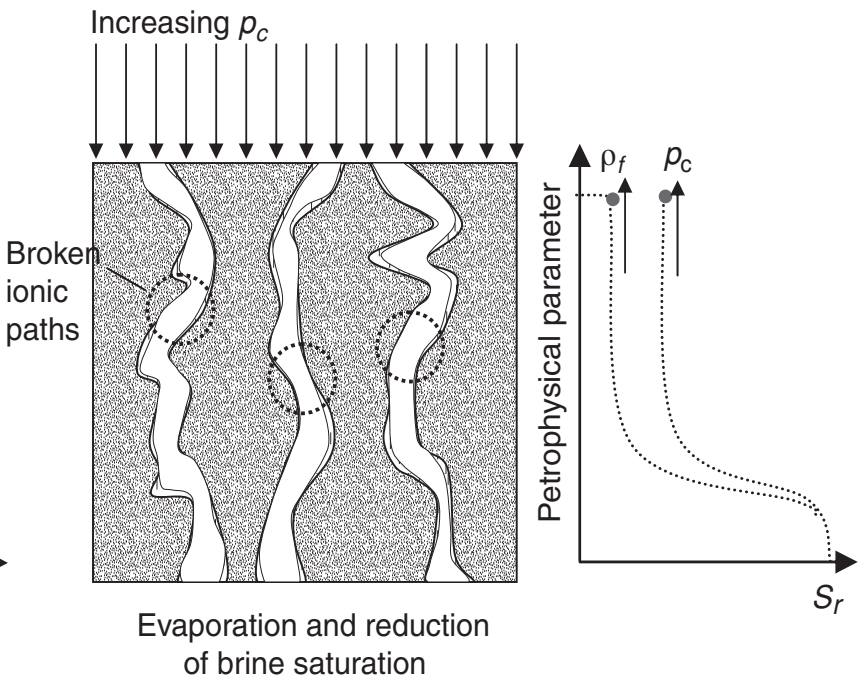

f) 


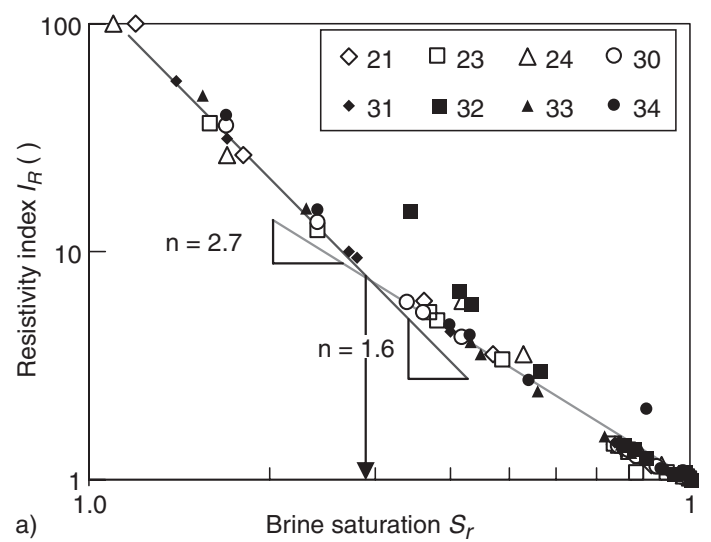

Figure 14

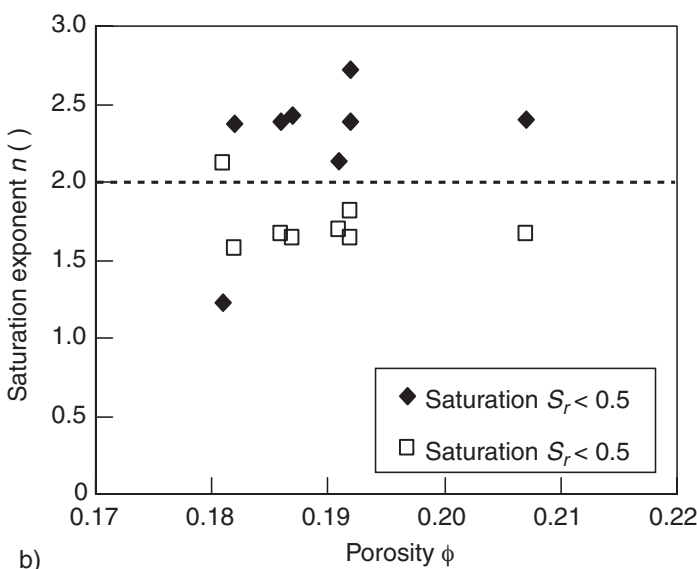

b)

Effect of brine saturation the saturation exponent in Berea sandstone specimens. a) Log-log plot of the resistivity index versus brine saturation. b) Saturation exponent versus porosity.

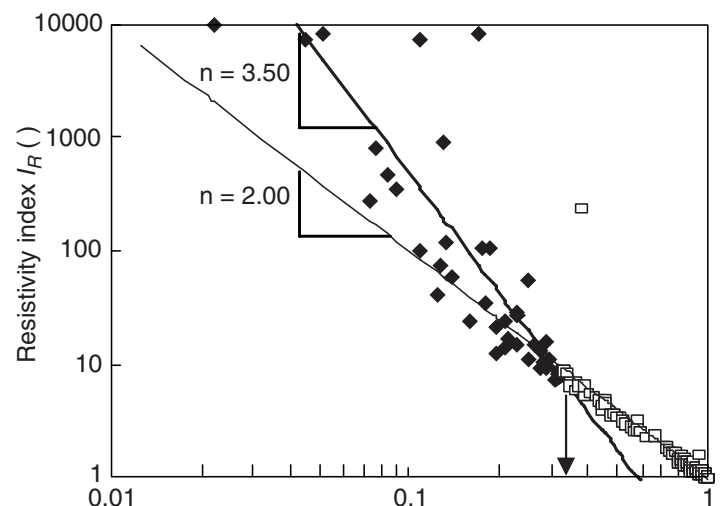

a)

Brine saturation $S_{r}$

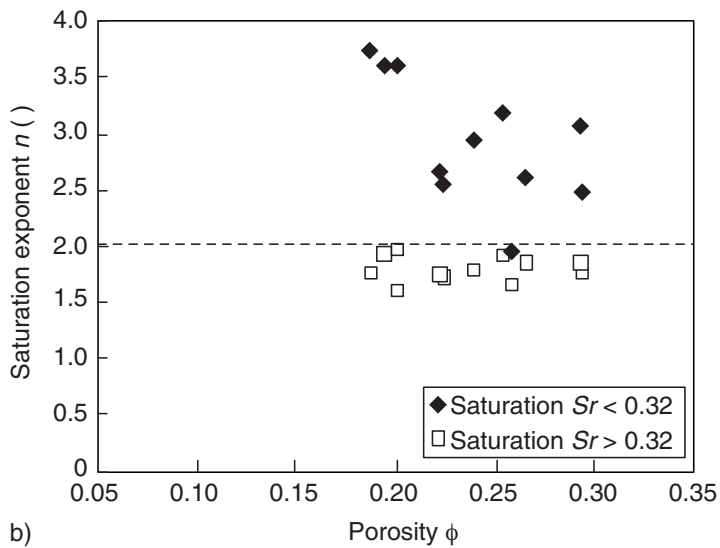

Figure 15

Effect of brine saturation on the saturation exponent in Quartz sandstone specimens. a) Log-log plot of the resistivity index versus brine saturation; (b) Saturation exponent versus porosity.

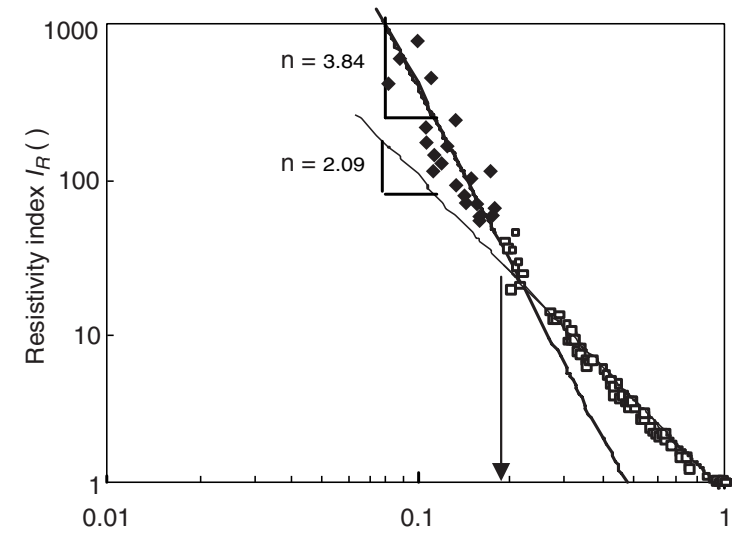

a)

Brine saturation $S_{r}$

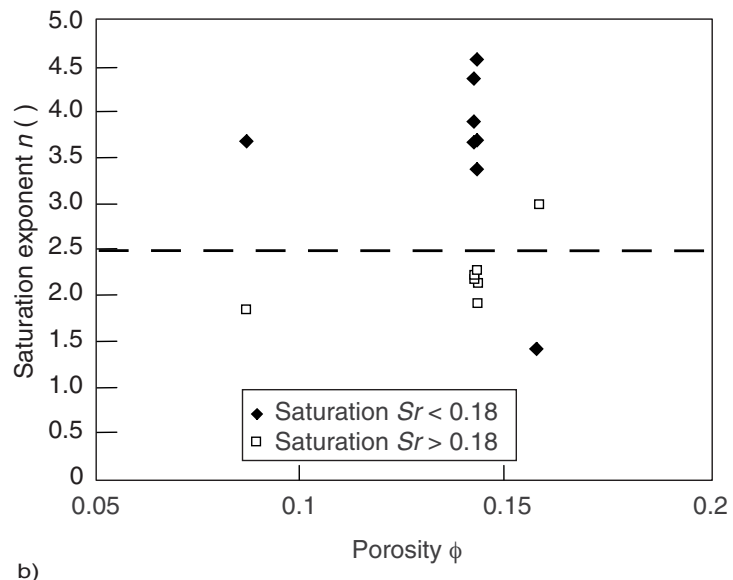

Figure 16

Effect of brine saturation on the saturation exponent in Limestone specimens. (a) Log-log plot of the resistivity index versus brine saturation; b) Saturation exponent versus porosity. 

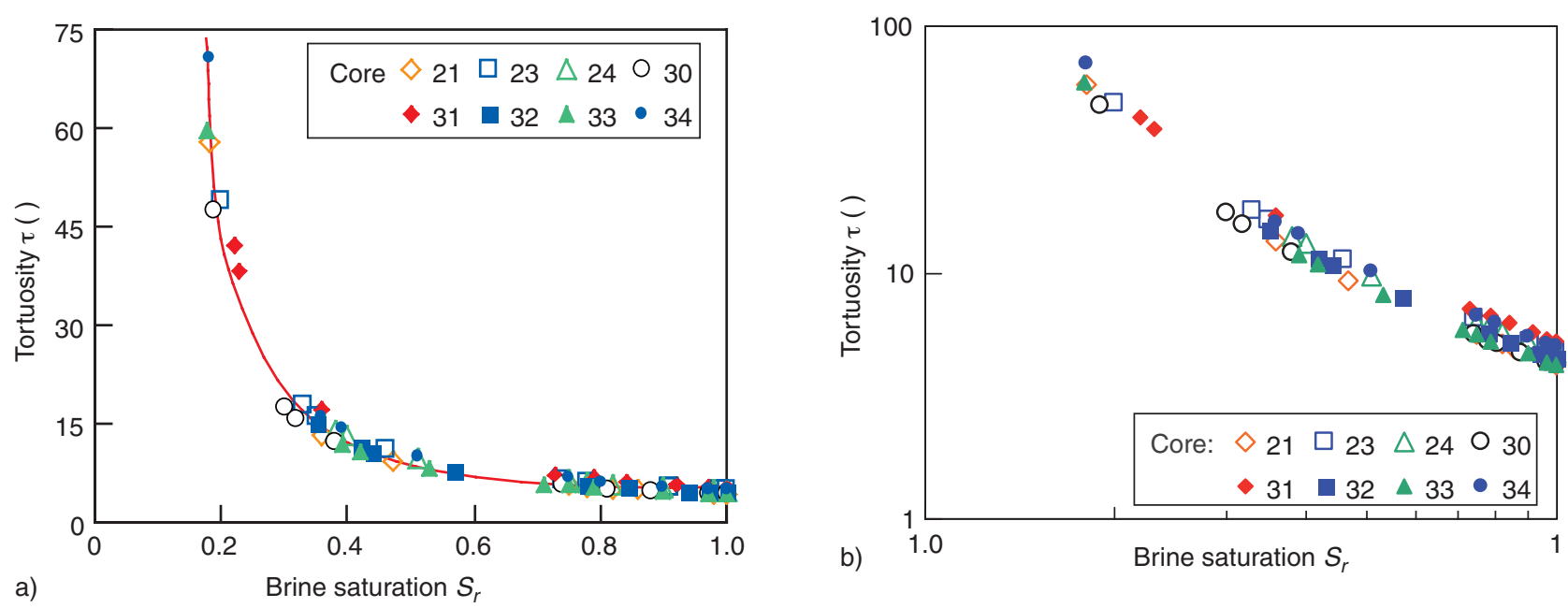

Figure 17

Calculated tortuosity versus degree of saturation in Berea sandstone specimens. a) Normal-normal plot.(b) Log-log plot.

pressure and electrical conductivity versus brine saturation curves. In the electrical resistivity measurements, the proposed silver-based paint electrodes prevent problems with electrode polarization for the tested frequency range.

Capillary pressure and electrical resistivity versus saturation curves show that the irreducible brine saturation is a parameter that depends on the type of conduction and its corresponding value of saturation at percolation. The two values of irreducible brine saturation (Figs. 10-12) yield an upper and lower bound limits that can be used to estimate limits to the production capacity of the porous medium. The detailed analysis of the data shows that the change in the value of the saturation exponent. This change occurs at the irreducible brine saturation as obtained with capillary pressure data. The change in the slope (Figs. 14a, 15a and 16a) seems to indicate the presence of discontinuous ionic path in porous media, however this observation must be confirmed with complementary testing techniques (e.g., micro-tomography). Finally, an equation to evaluate the tortuosity versus degree of saturation is proposed. Tortuosity results provide an indication of the distortion of the ionic path. Tortuosity appears to change at slow rates and the conduction paths show no sudden changes until the last brine percolation path is broken.

\section{ACKNOWLEDGMENTS}

The authors acknowledge the support of the department of Petroleum Engineering and the department of Civil and Environmental Engineering at the Louisiana State University and A\&M College.

\section{REFERENCES}

Anderson W.E. (1986) Wettability Literature Survey - Part 3. The Effects of Wettability in the Electrical Properties of Porous Media, J. Petrol. Technol.39, 13, 1371-1378.
Archie G.E. (1942) The electrical resistivity log as an aid in determining some reservoir characteristics, AIME T. 146, 54-67.

Attia M.A. (2005) Effects of petrophysical rock properties on tortuosity factor, J. Petrol. Sci. Eng. 48, 185-198.

Core Lab Instruments (2000) Soil Moisture Capillary Pressure Cell with Control Panel for 1, 3, and 15 bar plates (PPC-100A), Operation Manual. 2015 McKenzie, Suite 106. Carrolton, TX 75006, USA.

Diederix K.M. (1982) Anomalous relationships between resistivity index and water saturations in Rotliegend sanstone (the Netherlands), Trans. SPWLA. 23rd Annual Logging Symposium, Paper X.

Donaldson E.C., Siddiqui T.K. (1989) Relation between Archie saturation exponent and wettability, SPE Formation Evaluation 16790, 359-362.

Hewlett Packard (1984) Model 4276A LCZ Meter - Operation and Service Manual, Yokogawa-Hewlett-Packard, LTD. Takakura-Cho, Hachioji-Shi. Tokyo, Japan.

Klein K., Santamarina J.C. (1997) Broad-band frequency measurements with electromagnetic waves, Geotech. Test.J. 20, 168-178.

Klein K., Santamarina J.C. (2003) Electrical Conductivity in Soils: Underlying Phenomena, J. Environ. Eng. Geophysics 8, 4, 263-273.

Lewis M.G., Sharma M.M., Dunlap H.F., Dorfman M.H. (1988) Techniques for measuring the electrical properties of sandstone cores, 63th SPE Annual Technical Conference and Exhibition, Houston, TX, SPE paper 18178, 697-703.

Longeron D.G., Argaud M.J., Bouviever L. (1989b) Resistivity index and capillary pressure measurements under reservoir conditions using crude oil, 64th SPE Annual Technical conference and Exhibition, San Antonio, Texas, SPE paper No. 19589.

Longeron D.G., Argaud M.J., Feraud J.P. (1989a) Effect of overburden pressure, nature and microscopic distribution of fluid on electrical properties of rock samples, SPE Formation Evaluation 4, 194-202.

Mavko G., Mukerji T., Dvorkin J. (1998) The Rock Physics Handbook, CRC Press.

Mitchel J.K. (1993) Fundamentals of Soil Behavior, John Wiley and Sons.

Moss A.K., Jing X.D., Archer J.S. (2000) Laboratory Investigation of Wettability and Hysteresis Effects on Resistivity 
Index and Capillary Pressure Characteristics, J. Petrol. Sci. Eng. 24, 2-4, 231-242.

Santamarina J.C., Fratta D. (2003) Dynamic ElectricalMechanical Energy Coupling In Electrolyte-Mineral Systems, Transport Porous Med. 50, 153-178.

Santamarina J.C., Klein K.A., Fam M.A. (2001) Soils and Waves, John Wiley and Sons.

Santamarina J.C., Rinaldi V.A., Fratta D., Klein K.A., Wang Y.-H., Cho G.-C., Cascante G. (2005) A Survey of Elastic and Electromagnetic Properties of Near-Surface Soils, in Near-Surface Geophysics, Buttler D. (ed.), SEG. Tulsa, OK, pp. 71-87.

Swanson B.F. (1985) Microporosity in reservoir rock: Its measurement and influence on electrical resistivity, The Log Analyst, Nov.- Dec., pp. 42-52.
Telford W.M., Geldart L.P., Sheriff R.E. (1990) Applied Geophysics, Cambridge University Press.

Tiab D., Donaldson E.C. (1996) Petrophysics - The Theory and Practice of Measuring Reservoir Rock and Fluid Transport Properties, Gulf Publishing Company.

Wang H.F., Anderson M.P. (1982) Introduction to Groundwater Modeling, Freeman Press.

Worthington P.F., Pallatt N. (1992) Effect of variable saturation exponent on evaluation of hydrocarbon saturation, $S P E$ Formation Evaluation 7, 4, 331-336.

Final manuscript received in April 2007 